\title{
Perforated peptic ulcer over 56 years. Time trends in patients and disease characteristics
}

\author{
C Svanes, H Salvesen, L Stangeland, K Svanes, O Søreide
}

\begin{abstract}
Perforated gastroduodenal ulcer was studied in 1483 patients in the Bergen area during the years 1935-90 to discover time trends in age and sex, disease characteristics, treatment, and outcome. The male:female ratio fell from 10:1 to $1 \cdot 5: 1$, median age increased from 41 to 62 years. Most perforations were found in the duodenum in 1935-64, and in the pyloric and praepyloric area in 1965-90. There was a $10 \%$ occurrence of gastric ulcers throughout the study period. Ulcer site was related to age (more gastric and less duodenal perforations with increasing age) and sex (more pyloric and less duodenal ulcers among women). There were twice as many perforations in the evening compared with the early morning. The diurnal variation was more pronounced for duodenal and pyloric than for gastric and praepyloric perforations. Circadian and seasonal variation of ulcer perforation did not change during the 56 years studied. Treatment delay increased from median five hours to median nine hours. Infective complications and mortality fell with the introduction of antibiotics around $\mathbf{1 9 5 0 .}$ General complications has increased in recent years because of the increase of elderly patients. Among patients who died, the proportion with associated disease rose from 27 to $85 \%$ during the study period.

(Gut 1993; 34: 1666-1671)
\end{abstract}

Mr Crisp's description of perforated ulcer from $1843^{1}$ would fit into any modern textbook as far as symptomatology is concerned. From the available published works it can be deduced that the medical management, disease characteristics, and patient characteristics of perforated ulcer have changed since then..$^{2-11}$ To understand these changes it is important that confounding factors related to the geographical and hospital setting are kept constant and that the illness is studied over an extended period of time. This type of study has not been reported in recent publications.

This study describes the changing characteristics of perforated peptic ulcer in a well defined area on the west coast of Norway from 1935 to 1990 based on information from case notes. This offers a unique opportunity to investigate time trends in the patient population, disease characteristics (with detailed site classification), and aspects of management and outcome.

\section{Patients and methods}

A total of 1483 patients with acute perforated ulcer admitted to hospital in Bergen catchment area were studied. Patients were identified by several methods to achieve a complete registration based on computerised (1973-90) and manual (1935-72) recording systems. Case notes were identified based on diagnosis as well as surgical procedure for the years $1973-90$. For the years 1935-72 a card system based on diagnosis as well as consecutive recordings of the diagnosis of admitted or operated patients, or both were used for identification of patients. One thousand two hundred and thirty patients were treated at Haukeland hospital, 151 patients at the Deaconess hospital, 70 patients at Betanien hospital, and 32 patients at Red Cross and Florida hospitals.

For the 1296 patients treated at Haukeland and the Deaconess hospital (group I) the following information was obtained from case notes: patient characteristics, previous ulcer history, time of perforation, admittance and operation, preoperative diagnostic procedures, treatment, complications, and death. Information on location of the ulcer was obtained from operation notes as reported by the surgeon and examination of histological specimen(s) if available. For the remaining 191 patients (group II) information on patient characteristics, ulcer location, and operation performed was obtained from consecutive recordings of admitted and operated patients (protocols listing patient data, diagnosis, and date of admittance/operation). Analyses concerning sex, age, and type of operation were performed on data for all patients, the remaining analyses were carried out based on information for patients in group I.

\section{STATISTICAL ANALYSIS}

The data were analysed using the statistical program package $\mathrm{BMDP}^{12}$ on a personal computer. Analyses were based on contingency tables and included simple $\chi^{2}$ testing and tests for linear trend (P4F) to which the $p$ values in the text refer. Stepwise logistic analysis (PLR) was performed in a forward stepping manner with ulcer site as the dependent variable and sex, age, and year of performation as independent variables. Four analyses were performed, one for each anatomic location compared with the other three. The Tables show the confidence intervals and $p$ values estimated from the final models.

\section{Results}

PATIENTS AND CHARACTERISTICS OF DISEASE

Sex and age

Figure 1 shows the number of patients treated and the proportion of women in each five year period. The proportion of women increased 


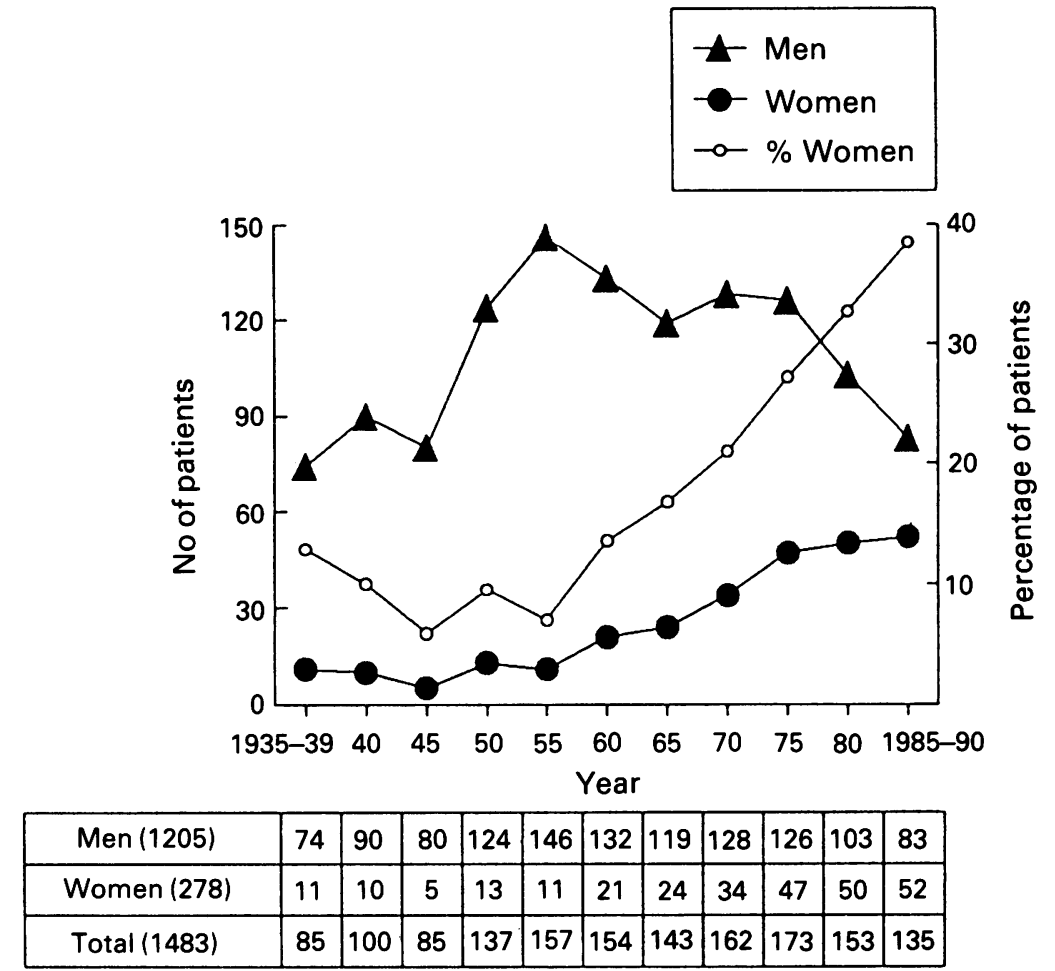

Figure 1: Number of men and women and proportion of women with perforated ulcer in five year periods from 1935 to 1990. of pyloric ulcers has been approximately $30 \%$. There were $5-10 \%$ praepyloric ulcers (perforations located within $2 \mathrm{~cm}$ proximal of the pylorus) during the first 30 years, after which the proportion increased gradually. Approximately $10 \%$ of the ulcers were located in the antrum, corpus or fundus ('gastric ulcers') throughout the study period.

Figure 3 shows the relation between age and ulcer site. With increasing age the number of duodenal perforations decreased while the number of gastric perforations increased. Figure 4 gives location of ulcer for men and women. Women had comparatively more pyloric and less duodenal perforations than men.

Table I summarises the comparative importance of age, sex, and time period for each ulcer site. The final models fitted the data well with $p$ values for goodness of fit of $>0 \cdot 1$. Adjusting for changes in age and sex distribution, there was a significant time trend for all ulcer types except gastric perforations. Duodenal perforations decreased while pyloric and praepyloric perforations increased during the study period. Duodenal and gastric perforations were related to age; duodenal ulcer affected the younger patients, gastric ulcer the older. There was a true sex difference for duodenal and pyloric perforations, pyloric perforations occurring comparatively more often in women and duodenal perforations in men. There was no sex difference in gastric perforations when adjusting for age. Similarly, pyloric and praepyloric ulcers were not related to age when adjusting for year of diagnosis.

\section{Circadian variation}

Figure 5A shows the circadian variation of ulcer perforation. There were twice as many perforations per hour in the evening compared with the early morning. Figure 5B shows the differences in diurnal variation according to ulcer location. For praepyloric and gastric ulcer, relatively more perforations occurred before 10 am than for pyloric and duodenal ulcer $(p=0.02)$. The patterns were similar for duodenal and pyloric ulcers, as well as for praepyloric and gastric ulcers. The circadian variation did not change during the study period (Fig 5C).

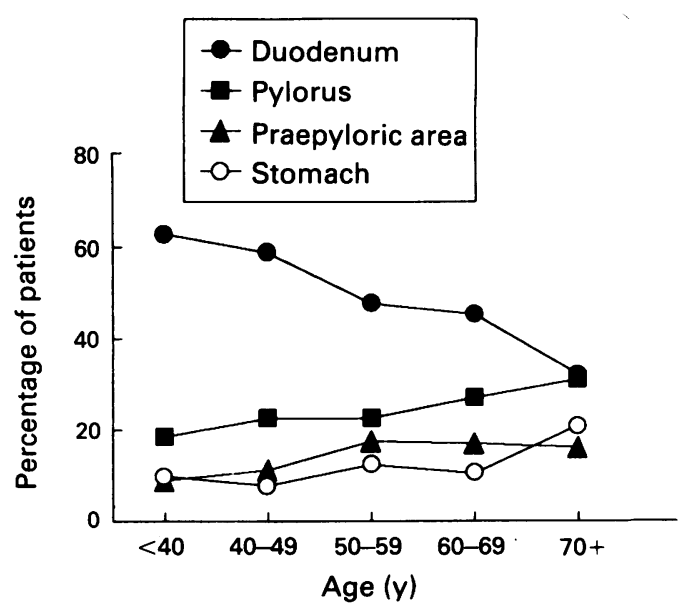

Figure 3: Frequency distribution of perforated ulcer according to ulcer location and age. 


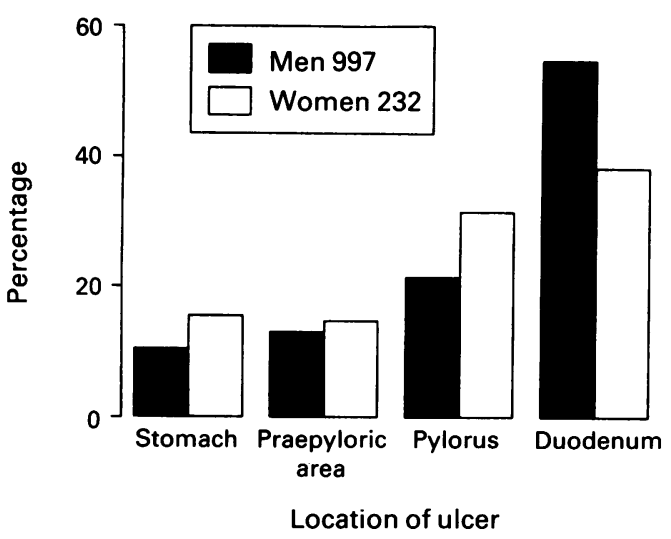

Figure 4: Frequency distribution of perforated ulcer according to ulcer location for men and women.

\section{Seasonal variation}

Figure $6 \mathrm{~A}$ illustrates the seasonal variation. More perforations occurred in early summer (May, June, July) and early winter (November, December). This pattern was mainly caused by the high proportion of duodenal and pyloric ulcers. Gastric and praepyloric ulcers did not show a clear seasonal variation (Fig 6B). The seasonal variation did not change during the study period (data not given).

\section{Previous dyspepsia}

Of 1146 patients with available data, $75 \%$ had had dyspepsia for more than one month before perforation. For the remaining 25\% perforation was the first presentation of ulcer disease. This finding was consistent throughout the study period irrespective of ulcer site. A larger proportion of women had perforation without previous dyspepsia $(28 \% \vee 18 \%$; $\mathrm{p}=0.01$; analysis of patients admitted 1970-90). Age was not significantly associated to previous dyspepsia (1970-90)

\section{Treatment delay}

Treatment delay, defined as time from perforation to operation, increased during the study period (linear trend: $p<0.001, n=1128$ ), also for the most recent five year period. The increase was mainly caused by increased in hospital delay (time from hospital admission to operation), while preadmission delay (time from perforation to admission) did not change significantly.

TABLE I Effect of year of diagnosis, age, and sex on distribution of ulcer locations

\begin{tabular}{|c|c|c|c|c|}
\hline & $\begin{array}{l}\text { Duodenum } \\
(n=592) \\
O R^{\star}(95 \% C I)+\end{array}$ & $\begin{array}{l}\text { Pylorus } \\
(n=286) \\
O R^{\star}(95 \% C I) \dagger\end{array}$ & $\begin{array}{l}\text { Praepyloric area } \\
(n=165) \\
O R^{\star}(95 \% C I) \dagger\end{array}$ & $\begin{array}{l}\text { Stomach } \\
(n=141) \\
O R^{\star}(95 \% C I) \dagger\end{array}$ \\
\hline \multicolumn{5}{|l|}{ Year: } \\
\hline $\begin{array}{l}1935-54 \\
1955-74 \\
1975-90\end{array}$ & $\begin{array}{l}1 \\
0.41(0.29 \text { to } 0.58) \\
0.31(0.21 \text { to } 0.46)\end{array}$ & $\begin{array}{l}1 \\
5.22(3.03 \text { to } 8.98) \\
5.13(2.95 \text { to } 8.94)\end{array}$ & $\begin{array}{l}1 \\
1.32(0.78 \text { to } 2 \cdot 23) \\
2.54(1.53 \text { to } 4.21)\end{array}$ & $\ddagger$ \\
\hline $\operatorname{Age}(y):$ & & & & \\
\hline $\begin{array}{l}<43 \\
43-58 \\
>58\end{array}$ & $\begin{array}{l}1 \\
0.80(0.60 \text { to } 1.07) \\
0.56(0.41 \text { to } 0.76)\end{array}$ & $\ddagger$ & $\ddagger$ & $\begin{array}{l}1 \\
0.88(0.55 \text { to } 1.39) \\
2.54(1.53 \text { to } 4.21)\end{array}$ \\
\hline $\begin{array}{l}\text { Sex: } \\
\text { Men } \\
\text { Women }\end{array}$ & $\begin{array}{l}1 \\
0.67(0.50 \text { to } 0.92)\end{array}$ & $1.46(1.05$ to 2.03$)$ & $\ddagger$ & 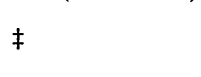 \\
\hline
\end{tabular}

$\star \mathrm{OR}=$ odds ratio obtained from logistic regression analyses; $+\mathrm{CI}=$ confidence intervals obtained from logistic regression analyses; †variable was non-significant and not included in final model $(p>0.05)$.
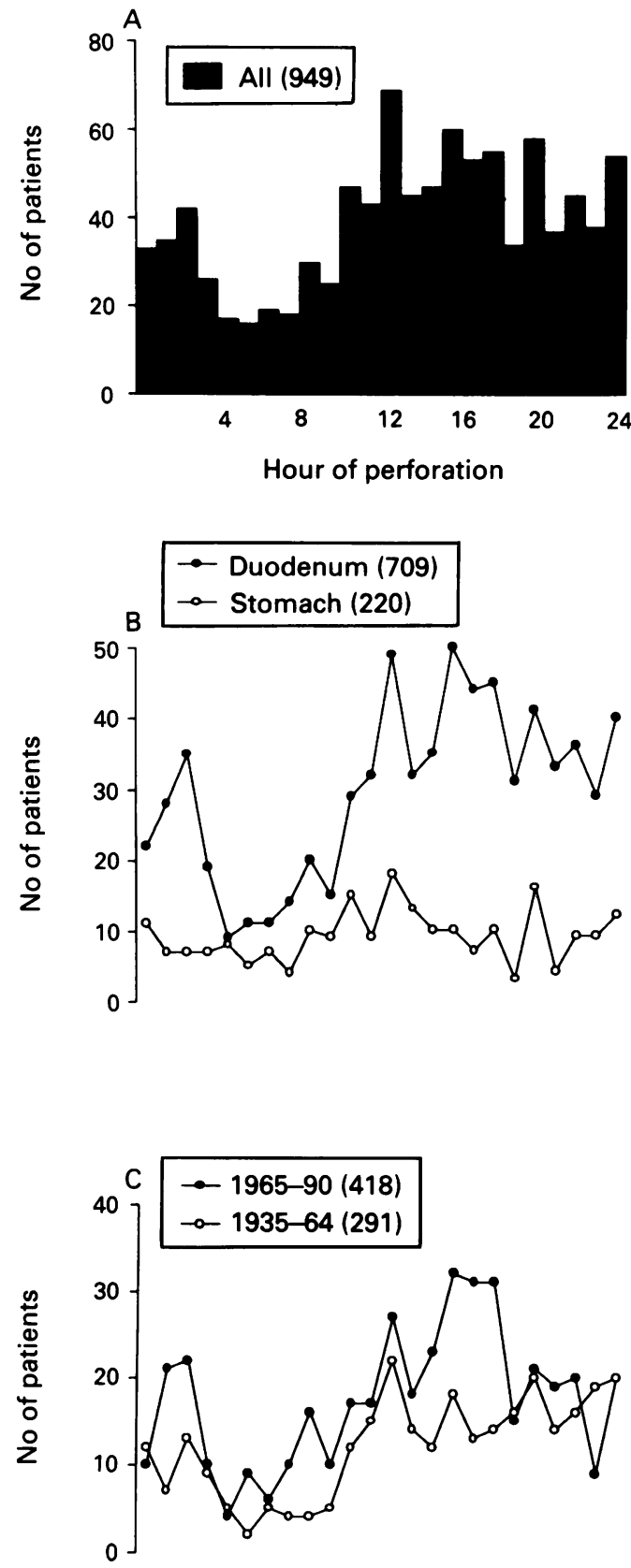

Figure 5: Circadian variation in ulcer perforation for $(A)$ all patients, $(B)$ according to ulcer location ('duodendum' = duodenum + pylorus, 'stomach' = praepyloric area + stomach), and $(C)$ after year of perforation (duodenal + pyloric ulcers). Data from patients with delay $<24$ hours.

\section{TREATMENT AND OUTCOME}

\section{Operations}

Figure 7 shows the operations performed for perforated ulcer. Of 1397 cases with available data, 1367 patients (98\%) had surgery. During the first five year period, similar proportions of patients had either suture, Billroth II type resection or suture plus gastroenterostomy. From 1940-60 resection was performed in about two thirds, the rest had a simple suture. Over the next 10 years treatment preference changed in favour of simple suture, which has been performed on nearly all patients since 1970 . Only 26 patients $(2 \%)$ were treated conservatively during the 56 year period. Seven patients had no treatment as the final diagnosis was made first at 

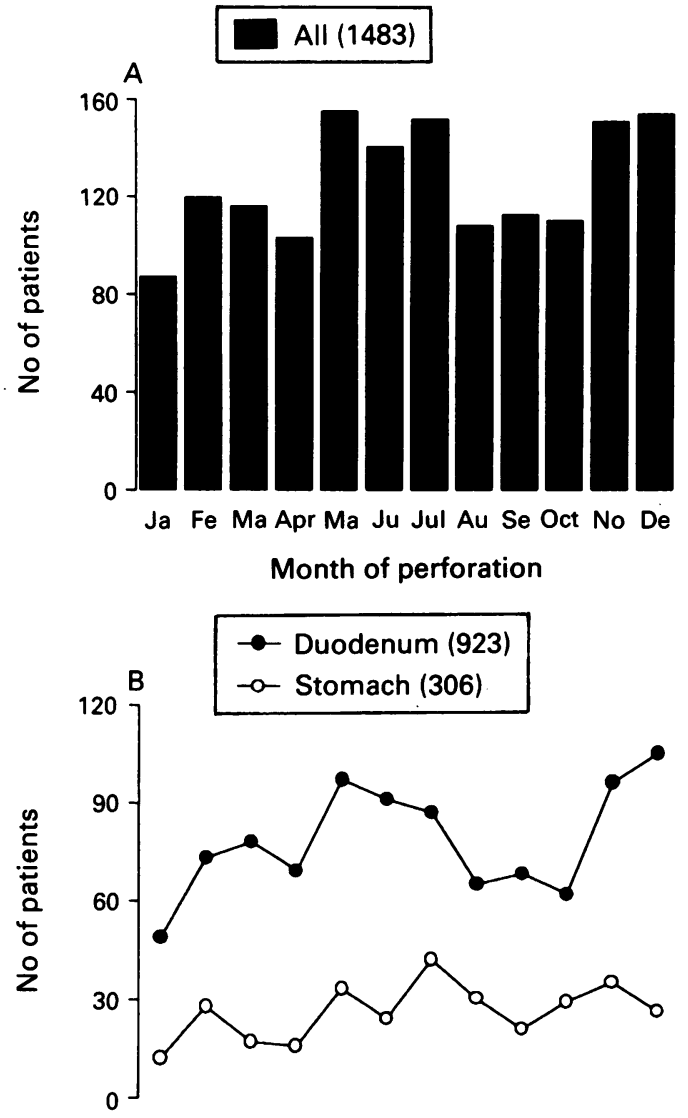

Figure 6: Seasonal variation in ulcer perforation for $(A)$ all patients and (B) according to ulcer location ('duodenum' = duodenum + pylorus, 'stomach' $=$ praepyloric area + stomach $)$ Numbers adjusted to 31 days/months.

postmortem examination, and eight patients died without treatment being started because of poor general condition. Of all patients, $75 \%$ were operated outside regular working hours $(8 \mathrm{am}-$ $4 \mathrm{pm})$.

\section{Antibiotics}

Antibiotics were introduced for the treatment of perforated ulcer in the late 'forties, and have been used in nearly all patients since 1950 (Fig 8).

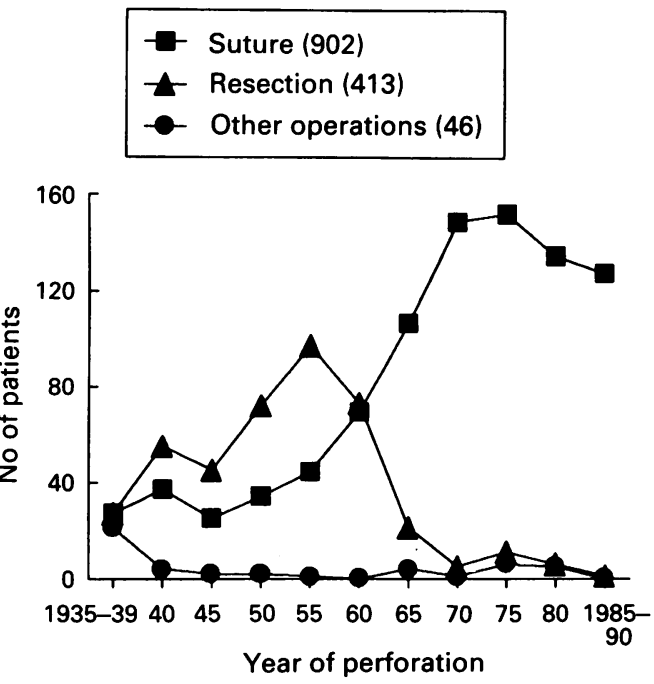

Figure 7: Operations for perforated ulcer 1935-1990 (other operations include suture + gastroenterostomy).

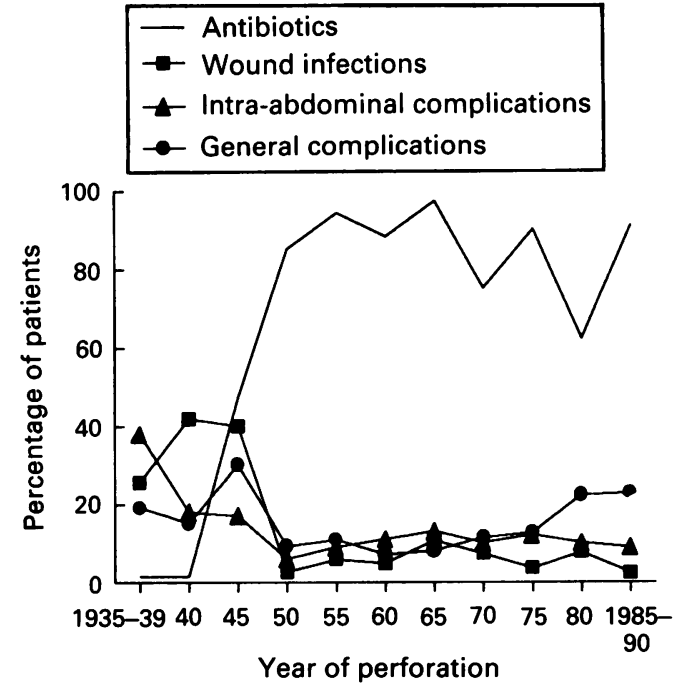

Figure 8: Complication rates $(n=1192)$ and use of antibiotics $(n=984)$ for patients with ulcer perforation 1935-1990.

\section{Postoperative complications}

Out of 1241 patients in group I who had surgery, data on complications were missing for 50 . Four patients died intra or immediately postoperatively. Of the rest, 334 patients (28\%) experienced one or more postoperative complication. Wound infections occurred in 113 patients $(10 \%), 143$ patients (13\%) had intra-abdominal abscesses or other abdominal complications such as anastomotic leakage, duodenal fistulas, peritonitis or bleeding. General complications (heart and respiratory problems) occurred in 169 patients $(14 \%)$. Forty three patients $(4 \%)$ had another operation during the primary hospital stay because of bleeding, fistulas, gastric retention or abscesses.

Figure 8 shows time trends in postoperative complication rates. There was a high incidence of infective complications before 1950 . In recent years the frequency of general complications increased. Elderly patients ( $>50$ years) had more complications than younger patients $(p=0.005)$, but no significant sex difference could be found $(p=0 \cdot 4)$. Ulcers located in the stomach carried a higher complication rate than duodenal, pyloric, and praepyloric ulcers $(\mathrm{p}=0.01$; Table II $)$.

\section{Deaths}

One hundred and one patients $(8 \%)$ died after perforation and related complications. Mortality decreased during the first part of the study period (1935-49), was comparatively stable during the years 1950-80, and increased in the last 10 years. Median age for the patients who died was $67 v 50$ years for the total patient

TABLE II Outcome of ulcer perforation by ulcer site * $^{*}$

\begin{tabular}{|c|c|c|c|}
\hline & $\begin{array}{l}\text { Complications } \\
\%(n)\end{array}$ & $\begin{array}{l}\text { Mortality } \\
\%(n)\end{array}$ & $\begin{array}{l}\text { Hospital } \\
\text { stay } \\
\text { median days }\end{array}$ \\
\hline $\begin{array}{l}\text { Duodenum }(n=244) \\
\text { Pylorus }(n=171)\end{array}$ & $\begin{array}{l}24 \cdot 6(57) \\
24 \cdot 1(41)\end{array}$ & $\begin{array}{l}7 \cdot 8(19) \\
7 \cdot 0(12)\end{array}$ & $\begin{array}{l}7 \\
8\end{array}$ \\
\hline $\begin{array}{l}\text { Praepyloric area } \\
(n=109) \\
\text { Stomach }(n=74)\end{array}$ & $\begin{array}{l}24 \cdot 5(26) \\
38 \cdot 6(27)\end{array}$ & $\begin{array}{c}2 \cdot 8(3) \\
17 \cdot 6(13)\end{array}$ & $\begin{array}{l}8 \\
9\end{array}$ \\
\hline
\end{tabular}

^Data from 1970-90 
population. The median age for death increased gradually from 50 years in 1935-44 to 78 years in 1985-90. Gastric ulcers carried a higher death rate than praepyloric, pyloric, and duodenal perforations $(p<0.001$; Table II).

Of the patients who died, 47 patients $(47 \%)$ had concomitant serious disease(s) at the time of perforation. Among the patients who died the proportion with associated severe disease increased from $27 \%$ in $1935-44$ to $85 \%$ in 1985-90 (linear trend: $\mathrm{p}<0.001$ ).

\section{Hospital stay}

Time spent in hospital decreased steadily during our study period (linear trend: $\mathrm{p}<0.001$ ). During the first 10 years, $75 \%$ of the patients spent more than two weeks in hospital, in 1985-90 49\% were discharged within seven days. Median stay in hospital for the whole period was 11 days. Women and elderly patients spent longer time in hospital than men and younger patients $(\mathrm{p}<0.001$ and $\mathrm{p}<0.001$; data from 1970-90). Patients with ulcer located in the duodenum spent less time in hospital than patients with pyloric, praepyloric or gastric ulcer $(p=0.001$; Table II, data from 1970-90).

\section{Discussion}

Mr Crisp's series ${ }^{1}$ consisted of $78 \%$ women of median age between 15 and 20 years. A 100 years later (1935-44) $89 \%$ of the patients affected by perforated ulcer were men of median age 40 years. Today (1985-90) there are $39 \%$ women of median age 69 years. These changes in age and sex are consistent with other reports from the Western world on ulcer perforation ${ }^{47101113}$ and ulcer disease in general. ${ }^{14-16}$

Major changes in the location of perforated ulcer have also been seen. In Mr Crisp's series there were $70 \%$ gastric ulcers of which half were close to the cardia. A 100 years later, such ulcers were rare and several authors reported that most perforations were located in the duodenum..$^{5617}$ This study shows that over the last 10 years (1980-90) pyloric and praepyloric perforations, encountered rarely decades ago, have exceeded duodenal perforations. It is remarkable that the proportion of gastric ulcer has remained stable over 56 years, particularly when considering the potential impact of ulcerogenic drugs. ${ }^{18}$

There are large variations in the published

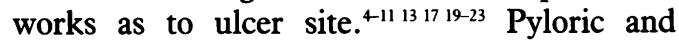
praepyloric ulcers are rarely specified as separate groups. This was a minor problem in former days as pyloric ulcers were rare, ${ }^{1517}$ but today this site represents a substantial number. ${ }^{24-26}$ Some authors claim that site classification is impossible as a precise anatomic distinction is difficult to assess because of inflammation. We have classified the perforations based on the surgeon's description, and argue that misclassification is probably not the reason for the time trends shown in Figure 2. The distinction is important as the four ulcer sites differ not only with regard to time trends, but also in patient characteristics, seasonal and circadian variation, treatment, and outcome (Figs 5 and 6; Tables I and II). No other study gives comparable information.
The diurnal pattern of ulcer perforation is remarkably constant irrespective of period of time or geographical setting. . $^{5101117}$ Our study disclosed a clear diurnal variation for perforation of duodenal ulcers, much less so for perforation of gastric ulcers. This may be related to variations between the ulcer sites in basic physiological mechanisms, while the stability in diurnal variation of duodenal perforation over time shows that these mechanisms are the same today as they were 50 years ago.

The issue of seasonal variation of ulcer perforation was first reported in $1903^{2}$ but is still controversial. Several studies ${ }^{25-822}$ point to an increased perforation rate in early summer and a decrease during the late summer consistent with our findings. Other reports differ entirely from ours $^{212728}$ or claim that there are no seasonal effects at all. ${ }^{1129}$ Differences in ulcer site may partly explain discrepancies in published works, while geographical differences cannot easily be detected. ${ }^{28}$ The patterns within defined geographical areas, however, are strikingly similar over different periods of time consistent with our findings. ${ }^{5-7}$

The stability of seasonal variation for duodenal ulcer throughout the study period makes an interesting historical experiment: dietary factors that were related to seasons in former days but not today, probably do not cause duodenal ulcer perforation. Some reports ${ }^{3031}$ propose an effect of salt on gastric ulcer but not on duodenal ulcer. Salted food was strongly related to seasons previously, but not after refrigerators and deep freezers became widely used. Thus, a causal relation between salt and duodenal ulcer does not seem plausible. Fresh fruit was seasonal until recent years, and our historical experiment suggests that related dietary factors can largely be excluded as causes of duodenal ulcer.

The increase in treatment delay from 1935 to 1990 in our study seems to be part of a general trend, as older publications report considerably shorter delays ${ }^{56820}$ than recent ones..$^{2426323}$ Factors associated with delay have been analysed for a subpopulation in a previously published paper. ${ }^{34}$ The development is alarming, and comparable studies should be carried out at other hospitals and for other emergencies.

Outcome of ulcer perforation in terms of complication rates and death improved considerably and was simultaneous with the introduction of antibiotics. Two other studies give data on death from perforated ulcer during the period studied. Both saw a decline around 1950,611 which can probably be attributed to the introduction of antibiotics.

In former days ulcer perforation could be fatal for otherwise healthy subjects. Today most deaths occur when patients have concomitant serious illness. We cannot find similar timetrend investigations in other published works. In Lanng's study from $1975-84,{ }^{35}$ however, $79 \%$ of those who died had serious concurrent disease, consistent with $70 \%$ during the last 15 years of our study.

The slight increase in death and complication rates during the last years of the study can largely be ascribed to patients being older and generally 
more ill. Age has been an important risk factor during all these years. ${ }^{36}$ Median age of those who died ( 28 years) has increased more than that of the total patient population ( 21 years), which indicates that age is an even more important risk factor today. A detailed study of factors influencing death has been published previously for a subgroup of this study population. ${ }^{36}$

Profound changes have been seen in perforated peptic ulcers in relation to ulcer site, age, and sex of the patients. Seasonal and circadian variation as well as proportion of gastric ulcers did not change during the study period. Treatment results have improved over 56 years in terms of reduced hospital stay, reduced mortality, and complication rates (taking age into consideration) and death now occurring almost exclusively in older patients with concomitant diseases. Despite vast investments in the organisation of health care, preadmission delay (attributed to primary health care and transportation) has not decreased, whereas inhospital delay continues to increase.

Supported by grants from The Norwegian Cancer Society.

1 Crisp E. Cases of perforation of the stomach. Lancet 1843; ii: $639-49$.

2 Jennings D. Perforated peptic ulcer. Lancet 1940; i: 395-8.

3 Jennings D. Perforated peptic ulcer. Lancet 1940; i: 444-7.

4 Illingworth CFW, Scott LDW. Acute perforated peptic ulcer. Frequency and incidence in the West of Scotland. $B M \mathcal{F}$ 1944; $2: 617-20$

5 Illingworth CFW, Scott LDW. Acute perforated peptic ulcer. Frequency and incidence in the West of Scotland. $B M \mathcal{J}$ 1944; 2 : 655-9.

6 Jamieson RA. Acute perforated peptic ulcer. Frequency and incidence in the West of Scotland. BMF 1955; 2: 222-7.

7 MacKay C. Perforated peptic ulcer in the West of Scotland: A survey of 5343 cases during 1954-63. BMF 1966; 1: 701-5.

8 DeBakey $M$. Acute perforated gastroduodenal ulceration. Surgery 1940; 8: 852-84.

9 DeBakey M. Acute perforated gastroduodenal ulceration. Surgery 1940; 8: 1028-75.

10 Cohen MM. Perforated peptic ulcer in the Vancouver area: a survey of 852 cases. Can Med Assoc 7 1971; 104: 201-5.

11 Hennessy E. Perforated peptic ulcer: mortality and morbidity in 603 cases. Aust NZ $\mathcal{Y}$ Surg 1969; 38: 243-51.

12 Dixon WJ, ed. BMDP statistical software. Berkeley: University of California Press, 1990.

13 Walt R, Katschinski B, Logan R, Ashley J, Langman M Rising frequency of ulcer perforation in elderly people in the United Kingdom. Lancet 1986; i: 489-92.
14 Sonnenberg A, Fritsch A. Changing mortality of peptic ulcer disease in Germany. Gastroenterology 1983; 84: 1553-7.

15 Coggon D, Lambert P, Langman MJS. 20 years of hospital admissions for peptic ulcer in England and Wales. Lancet 1981; i: 1302-4.

16 Kurata JH, Corboy ED. Current peptic ulcer time trends. An epidemiological profile. $\mathcal{F}$ Clin Gastroenterol 1988; 10: 259 68.

17 Yudine S. Etude sur les ulceres gastriques et duodenaux perfores. Fournal International de Chirurgie 1939; 4: 219-338.

18 McIntosh JH, Fung CS, Berry G, Piper DW. Smoking, nonsteroidal anti-inflammatory drugs and acetaminophen in nonsteroidal anti-inflammatory drugs and acetam

19 Koo J, Nogan YK, Lam SK. Trends in hospital admission, perforation and mortality of peptic ulcer in Hong Kong from 1970 to 1980 . Gastroenterology 1983; 84: 1558-62.

20 Noordijk JA. Perforated peptic ulcer. The results of treatmen in the Netherlands (1934-50). An analysis of 2551 cases. Archivum Chirurgicum Neerlandicum 1953; 5: 262-70.

21 Kozoll DD, Meyer KA. General factors influencing the incidence and mortality of acute perforated gastroduodenal ulcers. Surg Gynecol Obstet 1960; 111: 607-25.

22 Lazarus S. Perforated peptic ulcer in Israel. Gut 1964 5: 590-6.

23 Antila LE. Perforated peptic ulcer with generalised peritonitis. Early and late prognosis in 413 cases. Acta Chir Scand 1964; 128: 406-13.

24 Bodner B, Harrington ME, Kim U. A multifactorial analysis of mortality and morbidity in perforated peptic ulcer of mortality and morbidity in perforated

25 Gunshefski L, Flancbaum L, Brolin RE, Frankel A. Changing patterns in perforated peptic ulcer disease. Am Surg 1990; 56: $270-4$

26 Horowitz J, Kukora JS, Ritchie WP. All perforated ulcers are not alike. Ann Surg 1989; 209: 693-6.

27 Adler J, Ingram D, House T. Perforated peptic ulcer - a seasonal disease? Aust NZF Surg 1984; 54: 59-61.

28 Hall WH, Read RC, Mesard L, Lee LE, Robinette CD. The calendar and duodenal ulcer. Gastroenterology 1972; 62: $1120-4$.

29 Negre J. Seasonal periodicity of peptic ulcer: a myth. [Letter.] Lancet 1985; i: 1504-5.

30 Kato I, Nomura AMY, Stemmermann GN, Chyou PH. A prospective study of gastric and duodenal ulcer and its relation to smoking, alcohol and diet. Am $\mathcal{F}$ E pidemiol 1992; 135: $521-30$.

31 Sonnenberg A. Dietary salt and gastric ulcer. Gut 1986; 27 $1138-42$.

32 Mattingly SS, Ram MD, Griffin WO Jr. Factors influencing morbidity and mortality in perforated ulcer. Am Surg 1980 46: $61-6$.

33 Boey J, Wong J, Ong GB. A prospective study of operative risk factors in perforated duodenal ulcers. Ann Surg 1982; 195: 265-9.

34 Svanes C, Salvesen H, Espehaug B, Svanes K, Søreide O. Perforated peptic ulcer. An analysis of the increase in treatment delay 1935-85. Surgical Research Communications treatment delay 1989 ; $181-8$.

35 Lanng C, Palnæs Hansen C, Christensen A, Thagaard CS Lassen $\mathrm{M}$, Klærke A, et al. Perforated gastric ulcer. $\mathrm{Br} \mathcal{F}$ Surg 1988; 75: 758-9.

36 Svanes C, Espehaug B, Salvesen H, Søreide O, Svanes K. A multifactorial analysis of factors related to lethality following treatment of perforated gastroduodenal ulcer 1935-85. Ann Surg 1989; 209: 418-23. 